\title{
Surveying an Adriatic landscape: non- invasive survey approaches to pre-Roman sites in the ancient Ager Gallicus, Italy
}

Federica Boschi*

The Mapping Adriatic Landscape Project focuses on the systematic employment of non-invasive investigative techniques across the valleys of the Rivers Cesano, Nevola and Misa, in northern Marche, Italy. The Project aims to understand the dynamics of settlement and processes of urbanisation in the area.

Keywords: Italy, Ager Gallicus, pre-Roman, settlement, urbanisation

The Mapping Adriatic Landscape Project studies the valleys of the Rivers Cesano and Misa in central (northern Marche area) Italy - a territory known by the Romans as the Ager Gallicus -with the aim of improving the overall understanding of the early urbanisation processes in the region (Figure 1).

During the Iron Age (ninth to third centuries BC), Ager Gallicus was a complex 'cultural melting pot' of Piceni, Celts and Romans. Prolonged contact with Greece-mainly through maritime trading - is also attested between the sixth and fourth centuries BC (Luni 2003; Braccesi \& Luni 2004; Braccesi 2007). Although poorly documented, there is evidence for settlement patterns and interaction dynamics that needs to be explored and understood. The University of Bologna has a long tradition of studies focused on the dynamics of human occupation and landscape transformation in this part of the Marche (Dall'Aglio et al. 2007; Giorgi \& Lepore 2010; Silani 2017). Continuing this tradition, the systematic aerial and geophysical prospection employed by this new Project is contributing significantly to our understanding of the ancient colonisation of the region; new sites are being discovered and gaps in the knowledge concerning the region's proto-urban settlements and pre-Roman occupation are being filled (Boschi 2018).

Ager Gallicus is traditionally characterised by the presence of three Roman urban centres: Sena Gallica on the coast, and the municipia of Suasa and Ostra along the middle Cesano and Misa Valleys, respectively. While there is a firm understanding of the territory's Roman urban topography, the location, form and pattern of Iron Age and proto-urban settlements are far less clear.

\section{Methods}

The research strategy uses a multi-disciplinary approach, which integrates the results of noninvasive survey methods, such as aerial photography and geophysical prospection, along with

* University of Bologna, Department of History and Culture, Piazza San Giovanni in Monte, 2, 40124 Bologna, Italy (Email: federica.boschi5@unibo.it) 


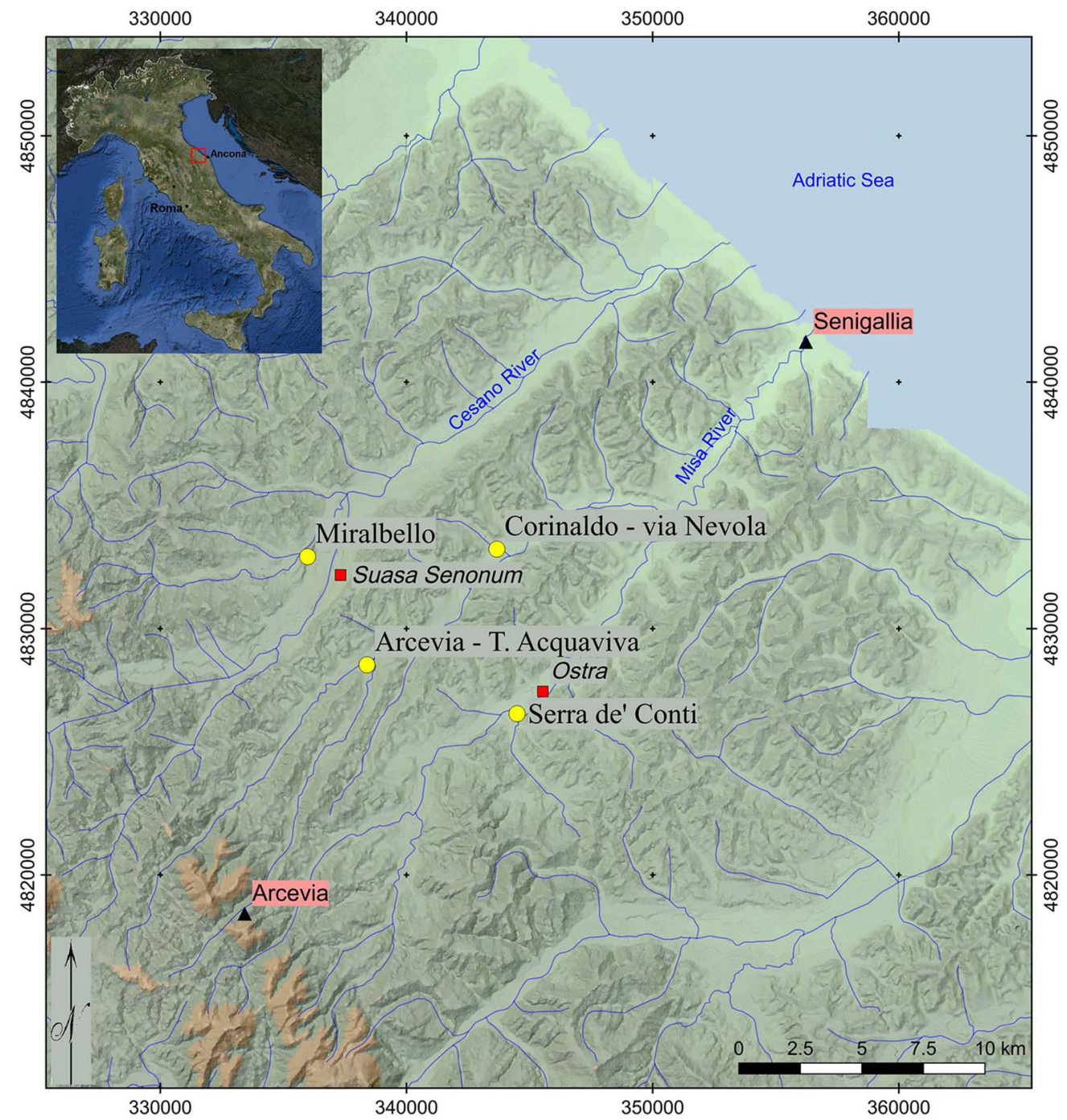

Figure 1. Valleys of the Cesano and Misa Rivers, with the locations of the main Roman towns and the newly discovered sites (yellow dots).

geomorphological studies, detailed topographical analysis, intensive field-walking survey and existing archaeological, historical and geomorphological data (Figure 2). Trial trenching, coring and small-scale excavation are also employed. Continuous feedback from the various collected datasets - even during excavation - is a constant feature of the strategy here.

Since 2012, aerial survey work has produced outstanding results, which have expanded the area of archaeological interest significantly. The aerial survey comprises a series of regular flights over the entire territory, collecting low-level oblique photographs and recording several cropmarks, which have subsequently been observed directly on the ground. Extensive and intensive field-walking survey and geophysical prospection have been undertaken to (C) Antiquity Publications Ltd, 2019 


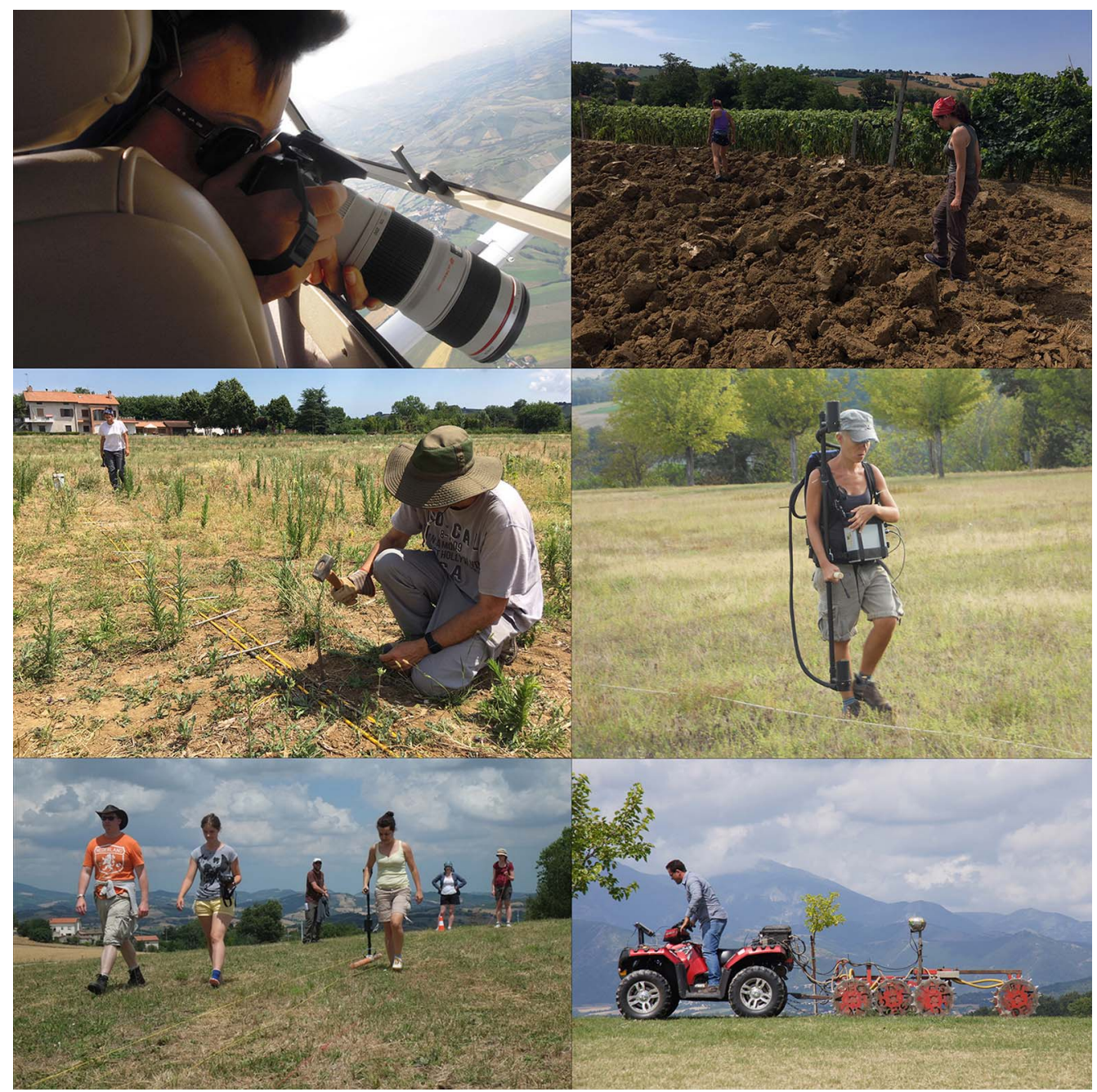

Figure 2. Methods and techniques used in the field.

investigate potential archaeological features. The general strategy for the geophysical survey was to ensure the acquisition of high-resolution data by combining different methods (e.g. ground-penetrating radar, resistivity, magnetometry, Overhauser, caesium and potassium methodologies). This integrated approach is contributing greatly to the interpretation and understanding of this territory's archaeological potential and its ancient population dynamics (Boschi 2016).

\section{Results}

The Project's recent investigations have provided important insights into Iron Age settlement patterns. Indeed, several new Iron Age sites have been discovered. Survey and geophysical prospection have enabled the identification of these new sites in both hilltop and river terrace

(C) Antiquity Publications Ltd, 2019 


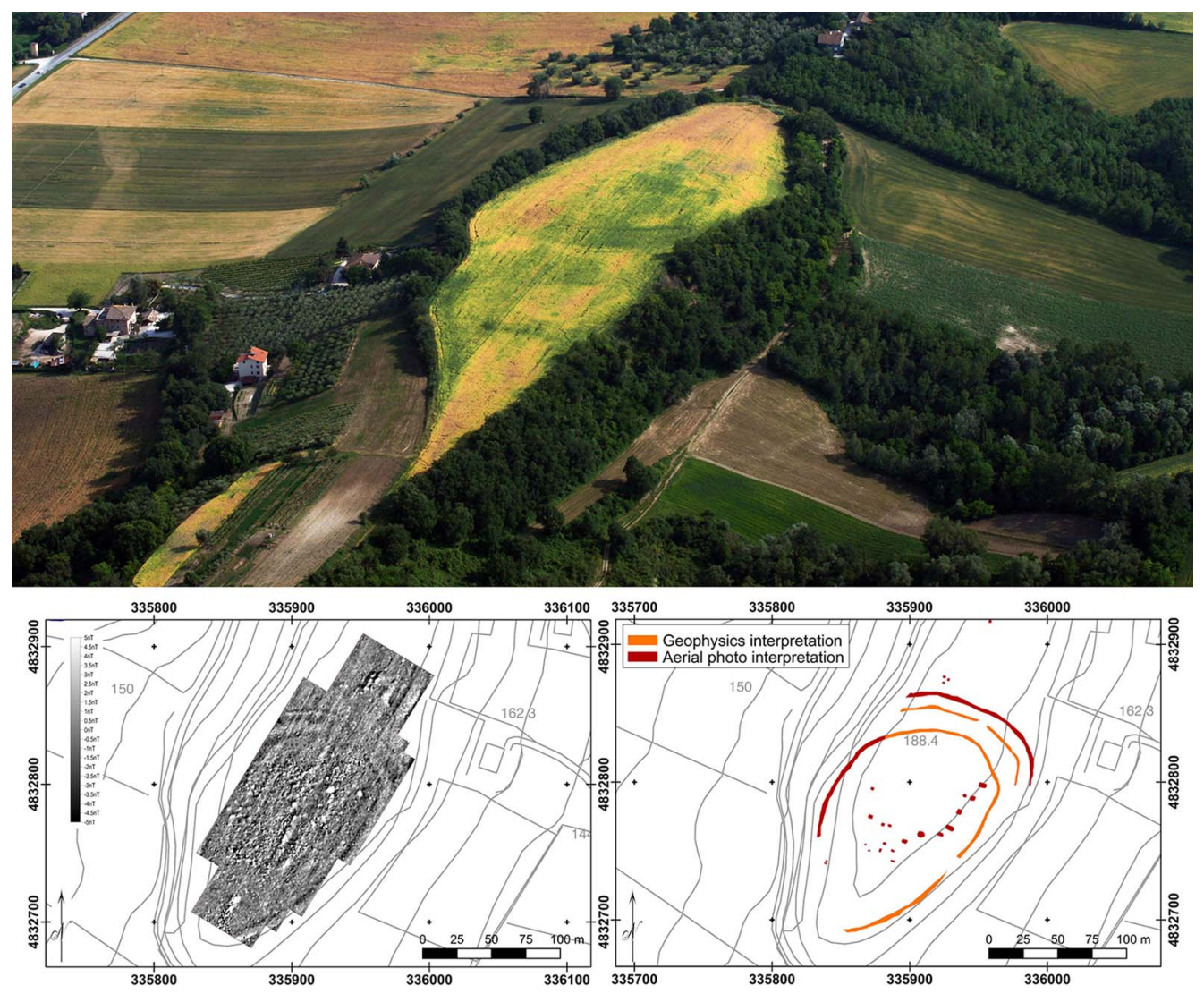

Figure 3. Miralbello (middle Cesano Valley); aerial view of the hilltop and geomagnetic survey on the plateau.

locations. In the former category, Miralbello, on the right bank of the River Cesano, stands out in terms of features and results (Figures 3-4). While the presence of pre- and protohistoric activity in the area was known from sporadic earlier finds, this wide-ranging strategy has now revealed new and important evidence that enables a greater understanding of the character and evolution of human occupation in this strategically crucial location in the valley. Geophysical mapping and its integration with aerial photography and detailed topographic survey, for example, has revealed the presence of banks and ditches, which improved on the natural defences that defined the settlement during its different occupation phases (Boschi 2018). The layout and strategic defensive location of the Miralbello site parallel several relatively small pre-Roman hilltop settlements attested in the southern Marche (Vermeulen et al. 2017).

The newly discovered sites on the river terraces were distinguished by circular cropmarks (Figures 5-6). A comparison with similar sites in the Marche region, at which direct investigation has already been undertaken, suggests that these are necropolises. The similarity with some of the most famous Piceni necropolises is clear, with the closest parallels being at Matelica, Numana-Sirolo and Fabriano. At these sites, groupings of former eighth- to sixth-centuries BC tumuli surrounded by circular ditches were identified and explored (Naso 2000).

(C) Antiquity Publications Ltd, 2019 


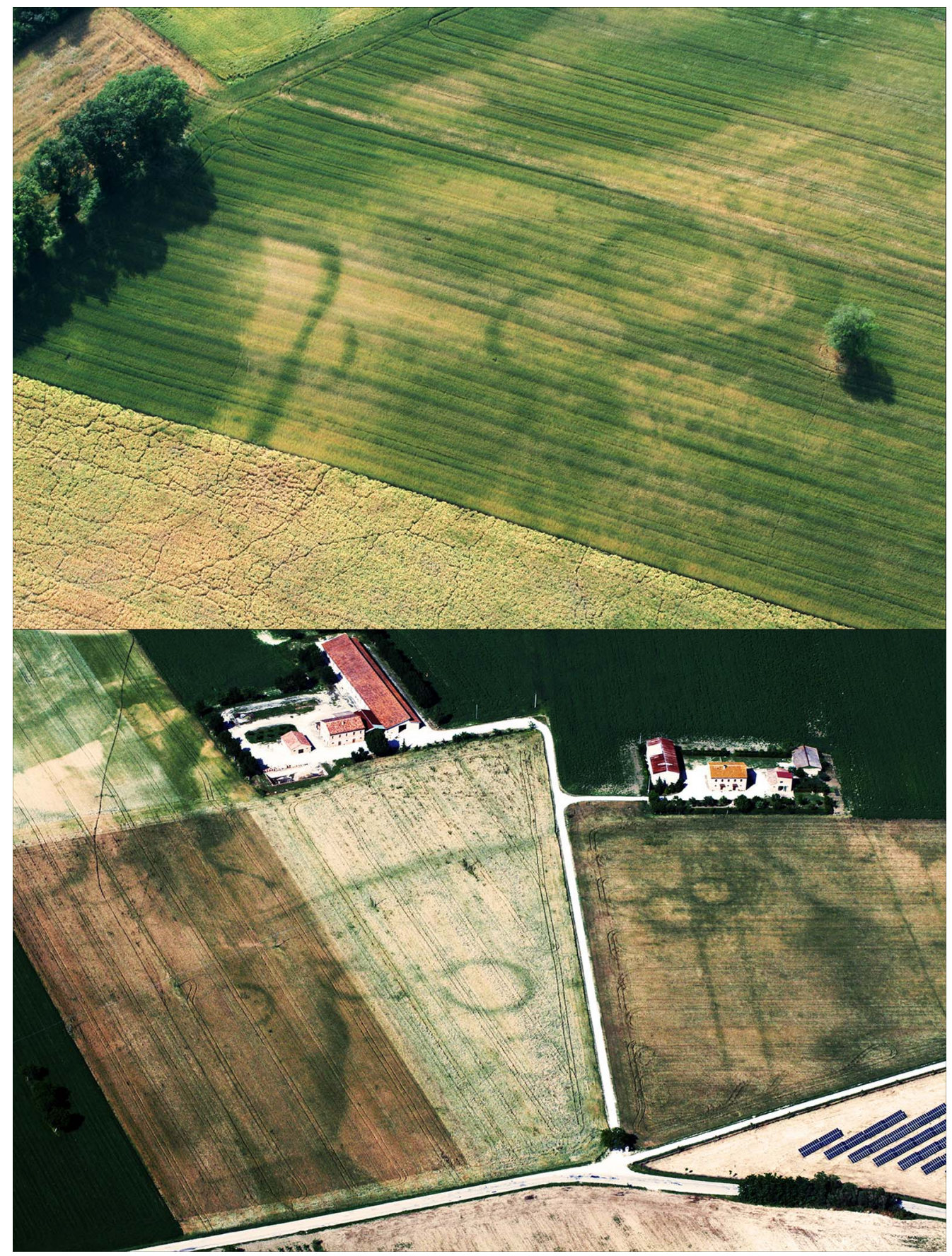

Figure 4. Circular cropmark sites along the River Misa (at Serra de' Conti).

Although the results require further interpretation, comparison with similar pre-Roman sites in the Marche region allows for preliminary reflections on the nature of these newly discovered sites. All these sites were founded in pre- or protohistory and, in some cases, were in

(C) Antiquity Publications Ltd, 2019 


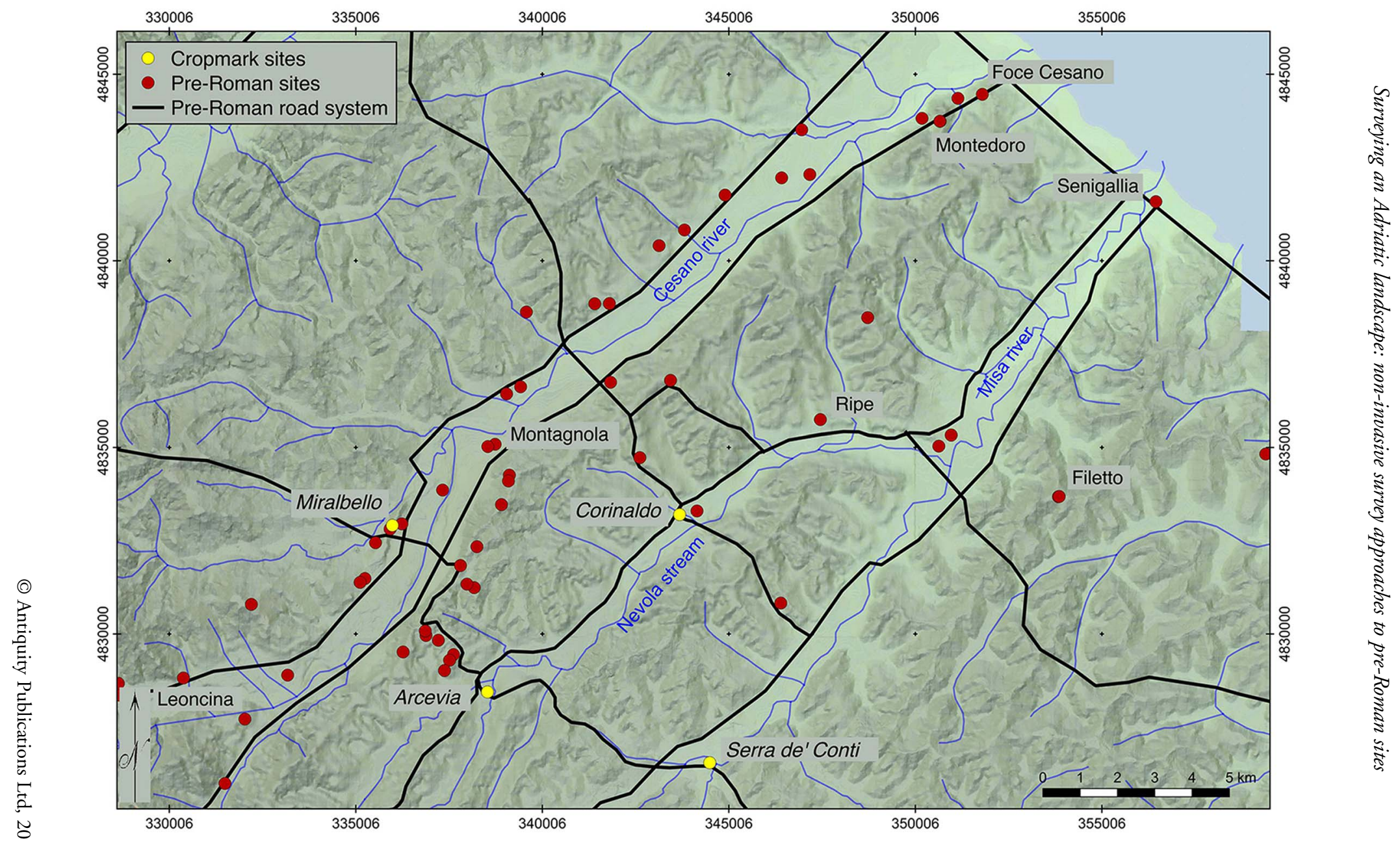

Figure 6. Contextualisation of the newly discovered sites (yellow dots) within the probable protohistoric road system and the mapping of the protohistoric sites from the field-walking survey.

\section{Project Gallery}


use until the early Roman period. There are many unresolved questions concerning the genesis and cultural associations of the earliest settlement phase, although it is probable that their chronology includes the first Iron Age-embracing the early phases of the Piceni culture. Whatever their true nature, whether domestic settlements or, as seems probable in the majority of cases discovered so far, as necropolises, these sites were all founded on low ground at the centre of river valley systems, in close association with the main river or its tributary streams, and with easy access to riverine transport routes. The hilltop sites, such as Miralbello, were probably established during the Final Bronze Age and the subsequent Iron Age, at a time when an elevated defensive location was preferred.

One of the most important outcomes of the Project's early work has undoubtedly been the provision of new data to fill some of the gaps in the territory's archaeological framework. The ongoing research presents a picture of pre-Roman settlements-in particular during the Late Bronze Age and the Iron Age-that became progressively less fragmented and more closely intertwined with the physical geography of the region (Figure 6).

\section{Acknowledgements}

The research presented here derives from long-term teamwork. I am particularly grateful to Michele Silani and Enrico Giorgi of the University of Bologna, Ilaria Venanzoni and the whole Soprintendenza Archeologia Belle Arti e Paesaggio delle Marche, for the fruitful collaboration and constant support to the project.

\section{References}

BoschI, F. 2016. Reading ancient cities. The contribution of the non-invasive techniques, in F. Boschi (ed.) Looking to the future, caring for the past. Preventive archaeology in theory and practice: 85-100. Bologna: Bononia University Press.

- 2018. Filling in the gaps: half-hidden pre-Roman settlements in the northern Marche (Italy). FOLD\&R Archaeological Survey 9: 1-17.

Braccesi, L. 2007. Terra di confine. Archeologia e Storia tra Romagna, Marche e San Marino. Roma: L'Erma di Bretschneider.

BracCesi, L. \& M. Luni (ed.). 2004. I Greci in Adriatico (volume 2; Hesperìa 15). Roma: L'Erma di Bretschneider.

Dall'Aglio, P.L., S. De Maria \& M. Podini. 2007. Territory, city and private life at Suasa in the
Roman Age. Journal of Roman Archaeology 20: 177-201. https://doi.org/10.1017/S1047759400005365

Giorgi, E. \& G. Lepore (ed.). 2010. Archeologia nella valle del Cesano da Suasa a Santa Maria in Portuno. Bologna: AnteQuem.

Luni, M. 2003. Greci in Adriatico, in M. Luni (ed.) Archeologia delle Marche. Dalla Preistoria all'età Tardoantica: 57-68. Firenze: Nardini.

Naso, A. 2000. I Piceni. Storia e Archeologia delle Marche in epoca preromana. Rome: Longanesi.

Silani, M. 2017. Città e territorio: la formazione della città romana dell'Ager Gallicus. Bologna: Bononia University Press.

Vermeulen, F., D. Van Limbergen, P. Monsieur \& D. Taelman. 2017. The Potenza Valley Survey (Marche, Italy): settlement dynamics and chancing material culture in an Adriatic valley between Iron Age and Late Antiquity. Rome: ESS.

Received: 20 November 2018; Accepted: 27 November 2018; Revised: 31 January 2019

(C) Antiquity Publications Ltd, 2019 